\title{
Boron Doped Graphene Oxide: Synthesis and Application to Glucose Responsive Reactivity
}

\author{
Md. Abdul Mannan ${ }^{1,2}$, Yudai Hirano' ${ }^{1}$ Armando T Quitain², Koinuma M1 and Tetsuya Kida ${ }^{2 *}$ \\ ${ }^{1}$ Department of Chemistry, Faculty of Science, Rajshahi University, Bangladesh \\ ${ }^{2}$ Graduate School of Science and Technology, Kumamoto University, 2-39-1 Kurokami, Chuo-ku, Kumamoto 860-8555, Japan
}

\begin{abstract}
In this present research, we have synthesized graphene oxide $(G O)$ by modified Hummer's method using graphite flake as starting material. Boron atoms were successfully doped into the $\mathrm{GO}$ framework with an atomic percentage of 1.64 1.89 at.\% by hydrothermal reduction using boric acid as a precursor. The presence of B-O, B-C and C-O bonds was predicted from the FT-IR spectral analyses. Shifting of XRD peak from $10^{\circ}$ to $26^{\circ}$ presumably indicated the reduction of $\mathrm{GO}$ by the incorporation of boron atoms. The crystalline defect was further confirmed by the Raman spectroscopy. Finally, the $\mathrm{C}=\mathrm{C}, \mathrm{C}-\mathrm{O},-\mathrm{BC}_{3},-\mathrm{BC}_{2} \mathrm{O},-\mathrm{BCO}_{2},-\mathrm{COO}-, \mathrm{B}_{2} \mathrm{O}_{3}$, and $\mathrm{C}-\mathrm{OH}$ chemical environments were precisely predicted by the XPS peak fitting analyses. The boron functionalized reduced graphene oxide (B-rGO) was subjected to the glucose adsorption reaction that showed significant glucose adsorption reactivity of $65 \sim 70 \%$ due to the high adsorption affinity of boron towards oxygen atoms of the glucose molecules.
\end{abstract}

Keywords: B-rGO; Hydrothermal reaction; Boric acid; X-ray photoelectron spectroscopy; Glucose adsorption

\section{Introduction}

Numerous researches have been conducted on graphene oxide (GO) since its first invention by Brodie [1]. The GO, a mono-layered material having $s p^{2}$-hybridized carbon along with $s p^{3}$-domain and different oxygen functionalities such as hydroxyl, carboxyl, and carbonyl groups showed distinctive mechanical, electrical and opto-electronical properties $[2,3]$. The outstanding physical properties of GO makes it an attractive material for fabrication of various nanocomposites, polymer materials, high performances microelectronic devices, energy storage materials, and for biomedical applications [4-6]. Moreover, due to the hydrophilicity character of GO, it could be easily dispersed in water. The oxygen functionalities in GO caused a severe decline in electrical properties, thermo mechanical stability and carrier mobility of carbonbased materials [7]. To minimize these problems, incorporation of non-metalic elements such as boron, nitrogen, sulfur fluorine, and phosphorous into the GO layer have been developed to improve the electrochemical properties $[8,9]$. Nitrogen-doped GO by chemical vapor deposition, thermal annealing, plasma irradiation methods have been reported for the application of electrical, enhancement of surface energy, increment of n-type carrier concentration and polarization energy [10-15]. However, drawbacks like incomplete purification and excessive amount of by products were remaining in the resulting GO materials and post treatment requires high temperature $\left(800 \sim 1200^{\circ} \mathrm{C}\right)$ which may cause structural degradation and morphological defects [16]. Boron and boron-nitrogen co-doped GO by simple thermal anneling and microwave assisted method have been reported for the application of supercapacitor, high performance anode material in $\mathrm{Li}$ ion battery, electromagnetic radiation in Ku-band etc. [17-19].

In this research, we report a novel approach for synthesizing boron doped reduced graphene oxide (B-rGO) through treating a mixture of graphene oxide (GO) and boric acid solution by simple hydrothermal condition in a closed vessel reaction chamber. The B-rGO was characterized using different techniques, and its application to glucose adsorption reactivity was evaluated. The B-rGO could be investigated for other applications such as sensor and/or energy storage devices.

\section{Experimental Methods and Materials}

\section{Chemicals and reagents}

The required materials such as sulfuric acid $\left(\mathrm{H}_{2} \mathrm{SO}_{4}\right)$, hydrochloric acid $(\mathrm{HCl})$, sodium nitrate $\left(\mathrm{NaNO}_{3}\right)$, potassium permanganate $\left(\mathrm{KMnO}_{4}\right)$, hydrogen peroxide $\left(\mathrm{H}_{2} \mathrm{O}_{2}\right)$, boric acid $\left(\mathrm{H}_{3} \mathrm{BO}_{3}\right)$, glucose, 3,5-dintrosalicylic acid (DNS), sodium potassium tartrate, sodium hydroxide $(\mathrm{NaOH})$ etc. all were purchased from Wako Pure Chemical Industries, Ltd., Japan.

\section{Synthesis of B-rGO}

Graphene oxide (GO) was synthesized by modified Hummer's method in which graphite flake was used as the starting material [20]. In a $1 \mathrm{~L}$ beaker, $4.0 \mathrm{~g}$ of $\mathrm{NaNO}_{3}$ weigh out and concentrated (N/M?) $\mathrm{H}_{2} \mathrm{SO}_{4}(148 \mathrm{~mL})$ were added and stirred for 30 minutes in an ice bath. Thereafter, $\mathrm{KMnO}_{4}(20.0 \mathrm{~g})$ was added slowly to the solution and stirred for 40 minutes at $35^{\circ} \mathrm{C}$. Then, distilled water $(184 \mathrm{~mL})$ was added while mixing for 15 minutes at $95^{\circ} \mathrm{C}$. All the steps are done in an oil bath. Further, $400 \mathrm{~mL}$ of $\mathrm{H}_{2} \mathrm{O}$ and about $25 \mathrm{~mL}$ of hydrogen peroxide $\left(\mathrm{H}_{2} \mathrm{O}_{2}\right)$ were added and stirred at $4000 \mathrm{rpm}$ for 10 minutes. Subsequently, the mixture was washed with $5 \% \mathrm{HCl}$ and centrifuged at $4000 \mathrm{rpm}$ for 30 minutes. The next step was exfoliation by sonication for $4 \sim 6 \mathrm{hrs}$. After that centrifuged the mixture at $10,000 \mathrm{rpm}$ for 30 minutes and the resulting supernatant was GO. Finally, it was dried for 3 to 4 days in an oven at $60^{\circ} \mathrm{C}$.

The obtained GO was functionalized by simple hydrothermal reaction method in which the reactor was equipped with an $8.8 \mathrm{~mL}$

*Corresponding author: Tetsuya Kida, Graduate School of Science and Technology, Kumamoto University, 2-39-1 Kurokami, Chuo-ku, Kumamoto 8608555, Japan, Tel: 096-342-3664; E-mail: tetsuya@kumamoto-u.ac.jp

Received August 30, 2018; Accepted October 01, 2018; Published October 21, 2018

Citation: Mannan MA, Hirano Y, Quitain AT, Koinuma M, Kida T (2018) Boron Doped Graphene Oxide: Synthesis and Application to Glucose Responsive Reactivity. J Material Sci Eng 7: 492. doi: 10.4172/2169-0022.1000492

Copyright: (c) 2018 Mannan MA, et al. This is an open-access article distributed under the terms of the Creative Commons Attribution License, which permits unrestricted use, distribution, and reproduction in any medium, provided the original author and source are credited. 
inconel batch. A schematic of the synthesis and functionalization process of GO with inconel batch reactor is shown in Figure 1. Typical $0.25 \mathrm{~g}$ of GO and $5.0 \mathrm{~mL}$ aqueous solution of boric acid with different concentrations were loaded into the reactor. Thereafter, desired reaction conditions such as temperature, pressure and time were set in the reaction period and are shown in Table 1 . The resulting samples were referred as functionalized reduced graphene oxide (B-rGO), which were collected, washed, filtered and dried overnight in an oven at $60^{\circ} \mathrm{C}$. Finally, the samples were characterized by using different instrumental techniques such as FT-IR, XRD, Raman, XPS, UV-vis, HPLC etc.

\section{Characterization of B-rGO}

Fourier transform infrared spectroscopy (JASCO, FTIR-4100) was used to determine different functional groups present in GO and functionalized B-rGO. The measurements were carried out in the wavelength range of 4000 to $400 \mathrm{~cm}^{-1}$. X-ray photoelectron spectroscopy (Perkin Elmer Phi 1600 ESCA) was used to determine the elemental compositions. The XPS was performed at Kumamoto University Instrumental Centre, Japan in which the $\mathrm{AlK}_{\alpha}$ was used as the X-ray source for irradiation of the sample surface. Solid state crystallographic structure was determined by X-ray diffractometer (Rigaku, MiniFlex600) using $\mathrm{CuK}_{\alpha}$ radiation source. Diffraction data were taken at $2 \Theta=5$ to $90^{\circ}$ with step energy $0.02 \mathrm{eV}$. Raman spectroscopy was used to evaluate the microstructure using JASCO NRS-3100 Laser Raman spectrophotometer. The Raman shift was recorded at 500-4000 $\mathrm{cm}^{-1}$ wavelength region.

\section{Determination of glucose adsorption capacity of B-rGO}

Glucose adsorption capacity of B-rGO was determined by HPLC and UV-vis spectroscopic methods. In this experiment, a typical reagent DNS (3,5-dinitrosalicylic acid) was used. It reacts with reducing sugar, forming 3-amino-5-nitrosalicylic acid, which strongly absorbs light at $540 \mathrm{~nm}$ wavelength region [21]. About $1.5 \mathrm{~g}$ DNS and $45.0 \mathrm{~g}$ sodium potassium tartrate were dissolved in $75.0 \mathrm{~mL}$ of distilled water and $30.0 \mathrm{~mL}$ of $2 \mathrm{M} \mathrm{NaOH}$, respectively. Then the sodium potassium tartrate and DNS solutions were mixed together and the volume was made up to $150 \mathrm{~mL}$ with distilled water and named it as DNS reagent. $50.0 \mathrm{mg}$ glucose was taken into $45.0 \mathrm{~mL}$ centrifuge tube and $12.0 \mathrm{~mL}$ deionized water was added then the tube was vortexed vigorously. Thereafter, $100.0 \mathrm{mg}$ of the B-rGO was loaded into different five test tubes and the contents were mixed well. All the test tubes were kept at room temperature and vortexed (MIXER UZUSIO, VTX-3000L) for 2 minutes after every 5 minutes. One test tube was taken after 20 minutes and centrifuged (speed and time). In this way, all the five test tubes were centrifuged at each of the following reaction times: 20, 30, 40, 60 and 120 minutes. $1.0 \mathrm{~mL}$ of the supernatant, $2.0 \mathrm{~mL}$ distilled water and $3.0 \mathrm{~mL}$ of the freshly prepared DNS solution were mixed together. Light yellow colored solution of the reaction mixture was put into boiling water bath for the period of about 5 minutes and then it was cooled by flowing cool tap water. The absorbance was taken by UV-vis spectrophotometer (JASCO, V-660 spectrophotometer) at 540 $\mathrm{nm}$. A standard curve of $\mathrm{D}(+)$ glucose was made with five different concentrations such as 1, 2, 3, 4, and $5 \mathrm{ppm}$. Unknown concentration was determined from the standard curve.

Concentration of the unknown sample solution was also determined via high performance liquid chromatography (JASCO, UV-970). In this case, a standard curve was also plotted and the glucose adsorption capacity was calculated by using the following equation. The following equation (1) was used in both the UV-vis and HPLC measurements:

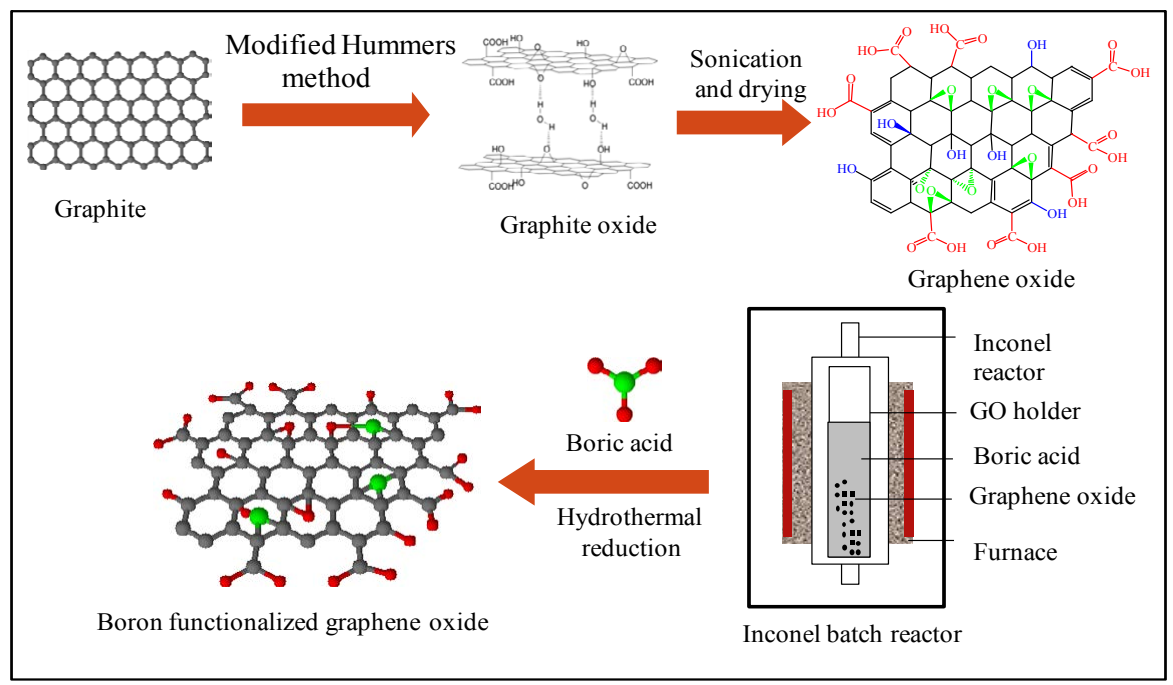

Figure 1: Schematic of the synthesis process of graphene oxide and boron doping by hydrothermal reaction using boric acid as the precursor.

\begin{tabular}{|c|c|c|c|c|c|c|c|c|c|}
\hline \multirow[t]{2}{*}{ Sample } & \multirow{2}{*}{$\begin{array}{l}\text { Reaction Temp. } \\
\left({ }^{\circ} \mathrm{C}\right)\end{array}$} & \multirow{2}{*}{$\begin{array}{c}\text { Reaction } \\
\text { Pressure } \\
\text { (MPa) }\end{array}$} & \multirow{2}{*}{$\begin{array}{l}\text { Reaction period } \\
\text { (h) }\end{array}$} & \multirow{2}{*}{$\begin{array}{l}\text { Conc. of boric } \\
\text { acid (M) }\end{array}$} & \multirow[t]{2}{*}{ Solution pH } & \multicolumn{4}{|c|}{ Elemental composition (at.\%) } \\
\hline & & & & & & c & $\mathbf{H}$ & 0 & B \\
\hline GO & - & - & - & - & - & $55.47 \pm 0.015$ & $1.83 \pm 0.05$ & $42.70 \pm 0.11$ & - \\
\hline B-rGO-1 & 250 & $\sim 22$ & 2 & 0.5 & 4.4 & $82.60 \pm 0.015$ & $1.40 \pm 0.05$ & $14.36 \pm 0.11$ & $1.64 \pm 0.01$ \\
\hline B-rGO-2 & 250 & $\sim 22$ & 2 & 1.0 & 4.5 & $84.90 \pm 0.015$ & $1.46 \pm 0.05$ & $11.88 \pm 0.11$ & $1.76 \pm 0.01$ \\
\hline B-rGO-3 & 300 & $\sim 22$ & 3 & 2.0 & 4.6 & $84.00 \pm 0.015$ & $1.79 \pm 0.05$ & $12.32 \pm 0.11$ & $1.89 \pm 0.01$ \\
\hline
\end{tabular}

Table 1: Reaction condition of hydrothermal doping of boron into GO lattice and their corresponding elemental composition. 
Citation: Mannan MA, Hirano Y, Quitain AT, Koinuma M, Kida T (2018) Boron Doped Graphene Oxide: Synthesis and Application to Glucose Responsive Reactivity. J Material Sci Eng 7: 492. doi: 10.4172/2169-0022.1000492

$$
\text { Glucose adsorption }(\%)=\frac{I_{\text {Initial }}-I_{\text {Final }}}{I_{\text {Initial }}} \times 100
$$

Where, $\mathrm{I}_{\text {Initial }}$ and $\mathrm{I}_{\text {Final }}$ are the initial and final concentration of the glucose in solution.

\section{Results and Discussion}

\section{FT-IR analyses}

Different functional groups present in the synthesized GO and B-rGO were assessed by FT-IR spectroscopic measurement. The FT-IR spectra of GO and B-rGO are shown in Figure 2a and 2b. It is observed that at least five distinctive peaks characteristics of GO are seen in the spectrum (Figure 2a). The peaks at $\sim 3300 \mathrm{~cm}^{-1}, 1736,1620,1232$, and $1060 \mathrm{~cm}^{-1}$, are assigned for GO by the stretching vibration of hydroxyl $(-\mathrm{OH})$, carbonyl $(\mathrm{C}-\mathrm{O})$, aromatic $(\mathrm{C}=\mathrm{C})$, epoxy $(\mathrm{C}-\mathrm{O}-\mathrm{C})$ and alkoxy (C-O) bonds, respectively, [22,23]. In the spectra of the B-rGO (Figure $2 \mathrm{~b})$, the hydroxyl peak became sharp and observed at around $3250 \mathrm{~cm}^{-1}$ due to incorporation of boron atoms and consequently the reduction of GO. There are three new peaks observed additionally at $1450 \mathrm{~cm}^{-1}$, 1200 and $1120 \mathrm{~cm}^{-1}$, respectively. These new peaks could be assigned for the stretching vibration of B-O, B-C and C-O bonds [24-26]. From the spectral analyses, therefore, we can suggest that the $\mathrm{B}-\mathrm{O}$ and $\mathrm{B}-\mathrm{C}$ bonds have been created in the GO network after boron functionalities.

\section{XRD analyses}

Crystalline structures of $\mathrm{GO}$ and $\mathrm{B}-\mathrm{rGO}$ were investigated by XRD analyses. XRD patterns for the samples were shown in Figure 3. A strong and intense peak at around $2 \Theta=10^{\circ}(d=0.44 \mathrm{~nm})$ has been observed which is assigned for the non-functionalized graphene oxide $[27,28]$. This characteristics peak in the XRD pattern of GO is completely disappeared in those of $\mathrm{B}-\mathrm{rGO}$, indicating that the oxygen containing groups of GO were efficiently removed at a certain percentage. Meanwhile, a new peak at around $2 \Theta=24.5^{\circ}(d=0.17 \sim 0.19$ $\mathrm{nm})$ has been found after hydrothermal functionalization with boric acid. This broad peak $\left(2 \Theta=24.5^{\circ}\right)$ suggests the exfoliation and reduction of GO with boron functionalities [29]. A significant decrease in the interlayer spacing distance from $d=0.44$ to $d=0.170 .19 \mathrm{~nm}$ also

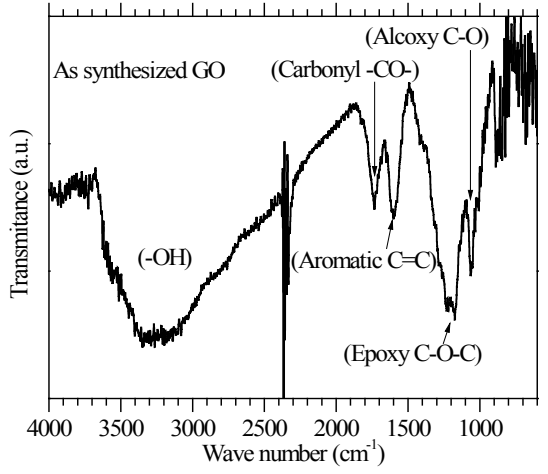

(a)

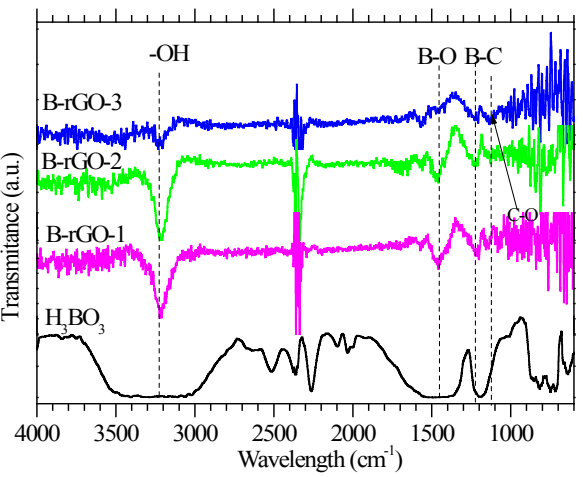

(b)

Figure 2: FT-IR spectra: (a) as-synthesized GO: (b) B-rGO

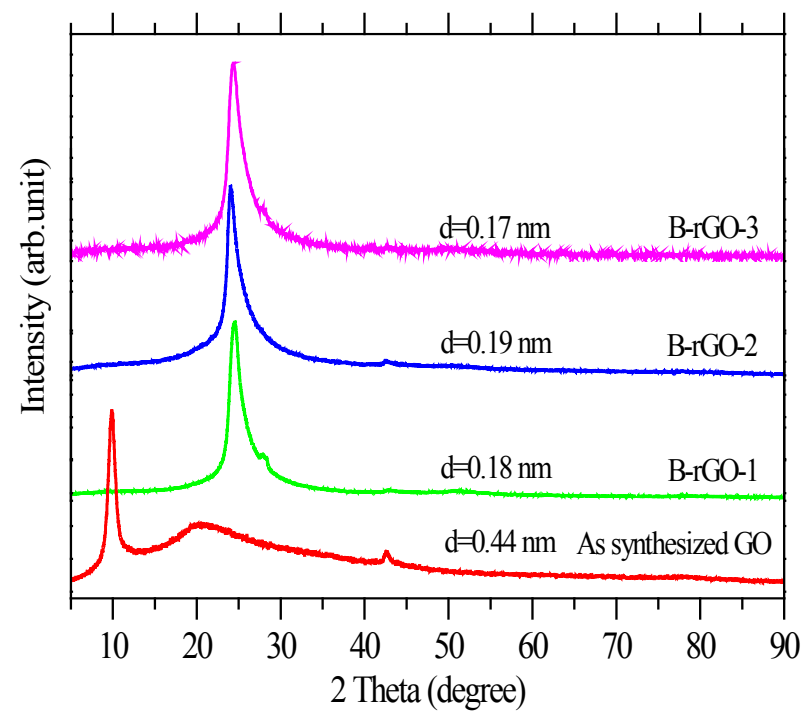

Figure 3: XRD patterns of the as-synthesized GO and B-rGO. 
support incorporation of boron atom into the GO layer. The absence of the peaks associated with oxygen functionalities in the FT-IR spectra (Figure 2a) agrees well with XRD results. This findings has also been coincided with the XPS analyses, since, the atomic concentration of boron was found to be 1.64 1.89 at.\% (Table 1) expressed in the following section.

\section{XPS analyses}

X-ray photoelectron spectroscopy (XPS) measurements were carried out in order to further investigate the chemical composition and chemical environment around carbon, oxygen and boron atoms for B-rGO samples. The XPS survey scan spectra showed the evidence of $\mathrm{C}, \mathrm{O}$, and B elements and are shown in Figure 4a. The elemental compositions (at.\%) were calculated from the XPS peak intensities and are shown in Table 1. It is seen that boron incorporation is increased up to 1.89 at.\% with the increase of reaction temperature and the concentration of boric acid. High resolution core shell XPS spectra of $\mathrm{C} 1 \mathrm{~s}, \mathrm{O} 1 \mathrm{~s}$ and $\mathrm{B} 1 \mathrm{~s}$ are carried out in order to explain the chemical environment around the $\mathrm{C}, \mathrm{O}$ and $\mathrm{B}$ atoms of the $\mathrm{B}-\mathrm{rGO}$ after boron doping. The deconvoluted $\mathrm{C} 1 \mathrm{~s}, \mathrm{~B} 1 \mathrm{~s}$ and $\mathrm{O} 1 \mathrm{~s}$ spectra are shown in Figure $4 \mathrm{~b}-4 \mathrm{~d}$. The $\mathrm{C} 1 \mathrm{~s}$ spectra could be deconvoluted into three peaks. The main peak located at the binding energy $284.2 \mathrm{eV}$ is due to the $s p^{2}-\mathrm{C}=\mathrm{C}$ chemical environment and the peak located at the binding energy region of $284.9 \mathrm{eV}$ could be suggested for the $\mathrm{C}-\mathrm{C} / \mathrm{C}=\mathrm{C}$ bonds. The shoulder peak at $285.8 \mathrm{eV}$ is due to the carbonyl C-O chemical environments [30-32]. The B1s could be deconvoluted into three component peaks Figure 4c. The peaks at 191.8, 192.6 and $193.2 \mathrm{eV}$ are assigned for the $-\mathrm{BC}_{3},-\mathrm{BC}_{2} \mathrm{O}$ and $-\mathrm{BCO}_{2}$ chemical environment, respectively, since the results are very good agreement with the reported value [30,33]. From the deconvolution of O1s spectrum, correspondingly, four components peaks at $530.7532 .0,533.2$ and $534.2 \mathrm{eV}$ were found which could be suggested for the carbonyl C-O, carboxylic -COO-, $-\mathrm{B}_{2} \mathrm{O}_{3}$ and hydroxyl -C-OH chemical environments, respectively [30]. These results are in good agreement with the FT-IR analyses (Figure $2 b$ ).

\section{Raman analyses}

Raman spectroscopy was used for indentifying the crystalline structure and quality of the as-received GO as well as B-rGO. The measurements have been done in the spectral region of $1000-2000 \mathrm{~cm}^{-1}$ using same laser power (632 $\mathrm{nm}$ laser excitation) for all the samples. The Raman spectra of the samples are shown in Figure 5. It is seen that the $\mathrm{D}$ band intensity is increased while the $\mathrm{G}$ band intensity is decreased for the as-synthesized GO and the B-rGO in comparison to that of the pristine graphite flake. The increase in intensity and broadening of both the $\mathrm{D}$ and $\mathrm{G}$ band confirmed the assimilation of oxygen containing functional groups as well as the assimilation of boron elements in the GO framework. This functionality caused the loss of crystalline structure of both the GO and B-rGO. Forward shifting of the G band position from 1595 to $1600 \mathrm{~cm}^{-1} \mathrm{~B}-\mathrm{rGO}$ suggesting the inclusion of boron atoms in the GO lattice leading to increase the disordered structure [34]. The increment in the $\mathrm{I}_{\mathrm{D}} / \mathrm{I}_{\mathrm{G}}$ ratio clearly demonstrates the formation of defects in the graphene sheets by boron doping that might leads to considerable changes in the structural properties, electrical and other physicochemical properties.

\section{Glucose adsorption analyses by UV-vis and HPLC analyses}

Glucose responsive adsorption reactivity of the B-rGO was compared with those of the synthesized GO and with the pristine graphite flake. The results are shown graphically in Figure 6. It was found that the adsorption reactivity of graphite and GO were found to be almost comparable. The highest adsorption was observed (65 70\%) for B-rGO in the reaction period of 40 minutes and then the reactivity was declined with reaction time. The adsorption mechanism could be (a)

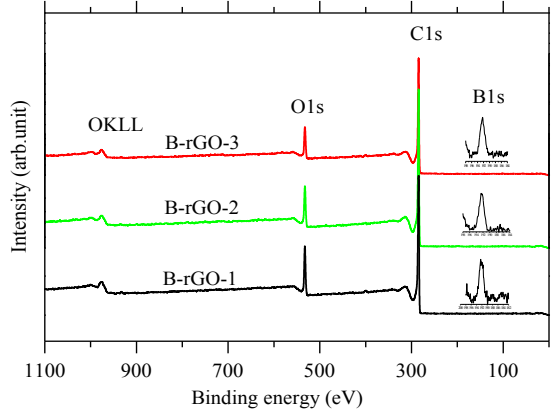

(c)

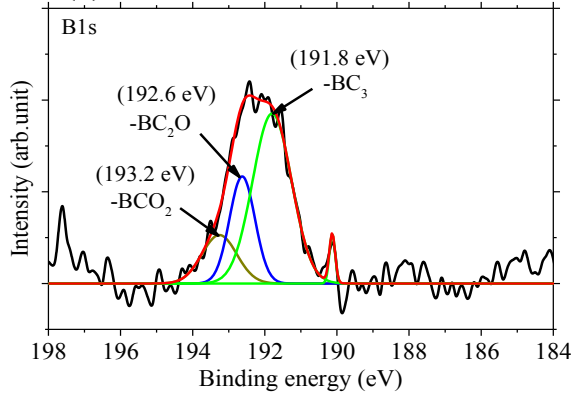

(b)

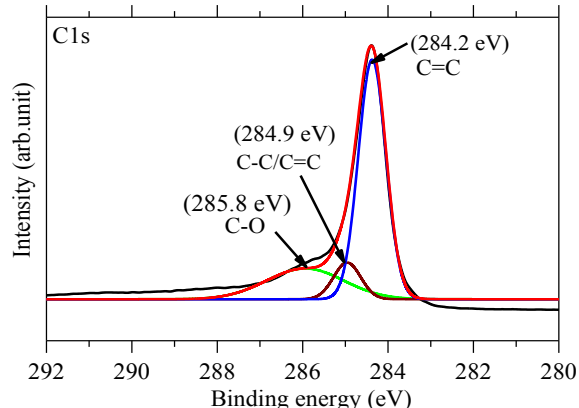

(d)

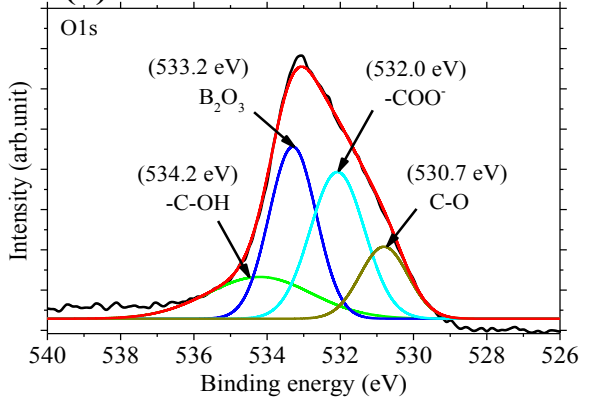

Figure 4: XPS spectra: (a) survey scan XPS spectra of B-rGO, (b) High resolution core shell C1s, (c) B1s and (d) O1s XPS spectra of B-rGO. The spectra were taken at the step energy of $0.02 \mathrm{eV}$. 


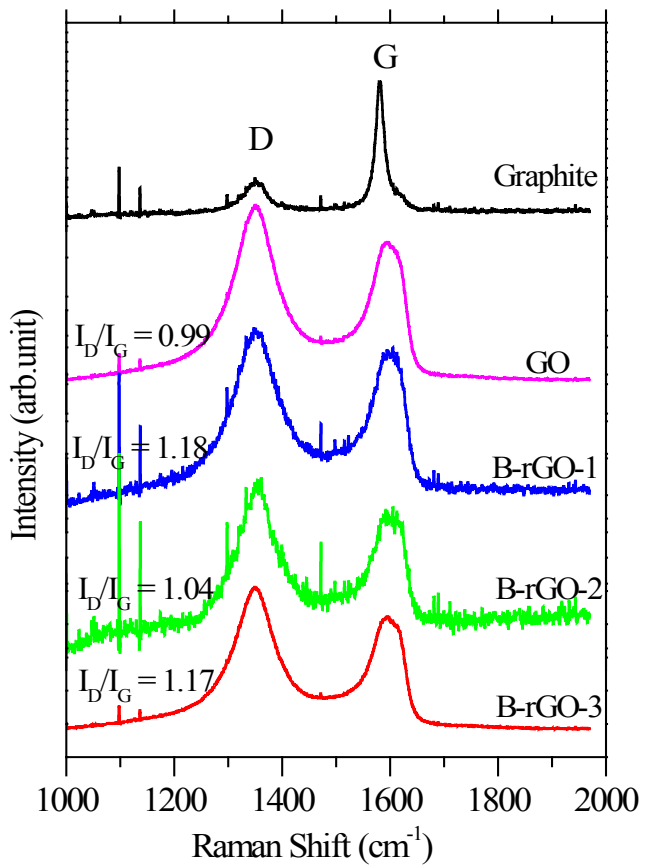

Figure 5: Raman spectra of graphite flake (top spectrum), GO, and B-rGO.

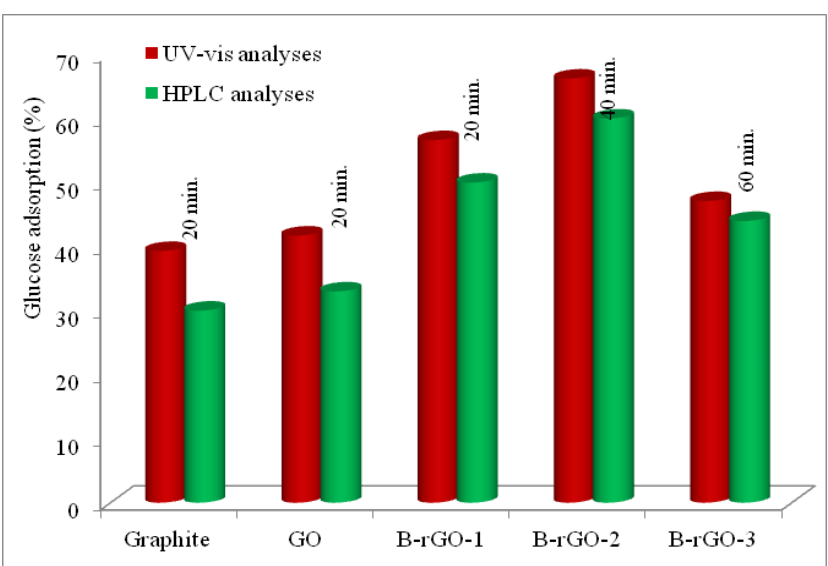

Figure 6: Graphical presentation of glucose adsorption reactivity of graphite, $\mathrm{GO}$ and B-rGO

initially presumed that the boron atoms of B-rGO could bind to the C-1/C-2 diol and C-4/C-6 diol of glucose in its hexopyranose form [35]. Another possibility is that the binding between the boron atoms of B-rGO and the oxygen atoms of the furanoside form of free hexoses [36]. The plausible mechanism of the binding site is shown in Figure 7. From the results, it could be acclaimed that the B-rGO could be used as the blood glucose biosensing receptors. However, more researches have to be done to confirm the bio-sensing reactivity of the B-rGO.

\section{Conclusions}

We have synthesized GO by modified Hummer's method using graphite flake as the starting material and boron doping was successfully achieved by hydrothermal reaction using boric acid as precursor. FTIR confirmed the presence of different functional groups in the GO and $\mathrm{B}-\mathrm{C}$ and $\mathrm{B}-\mathrm{O}$ bonds in $\mathrm{B}-\mathrm{rGO}$. The crystalline defect structural was

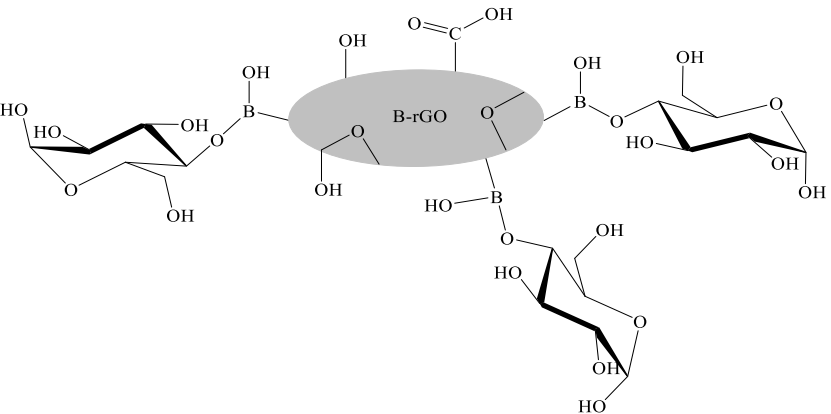

Figure 7: The possible mechanism of the glucose binding site with boron atoms of $\mathrm{B}-\mathrm{rGO}$.

confirmed by XRD and Raman spectroscopic analyses. This method gives about 1.64 1.89 at.\% of boron doping onto the GO lattice which was confirmed by XPS. The B-rGO exhibited significant glucose responsive adsorption reactivity with the adsorption percentage of $65 \sim 70 \%$. The B-rGO could be used as glucose adsorption bio-sensing applications.

\section{Acknowledgements}

The author gratefully acknowledged The President of JASSO for providing financial support under JASSO Fellowship Program. Special thanks go to the students of Prof. Kida's laboratory for giving their continuous help in completing of the research work.

\section{References}

1. Brodie BC (1859) On the atomic weight of graphite. Philos Trans R Soc London 149: $249-259$.

2. Geim AK, Novoselov KS (2007) The rise of graphene. Nat Mater 6: 183-191.

3. McAllister MJ, Li JL, Adamson DH, Schniepp HC, Abdala AA, et al. (2007) Single sheet functionalized graphene by oxidation and thermal expansion of graphite. Chem Mater 19: 4396-4404.

4. Lightcap I, Kamat PV (2013) Graphitic design; prospects of graphene-based nanocomposites for solar energy conversion, storage, and sensing. Acc Chem Res 46: 2235-2243.

5. Huang X, Qi X, Boey F, Zhang H (2012) Graphene-based composites. Chem Soc Rev 41: 666-686.

6. Zhu Y, Murali S, Cai W, Li X, Suk JW, et al. (2010) Graphene and graphene oxide: synthesis, properties, and applications. Adv Mater 22: 3906-3924.

7. Dreyer DR, Park S, Bielawaski CW, Ruoff RS (2010) The chemistry of graphene oxide. Chem Soc Rev 39: 228-240.

8. Stephan O, Ajayan PM, Colliex C, Redllich P, Lambert JM, et al. (1994) Doping graphite and carbon nanotube structures with boron and nitrogen. Science 266: 1683.

9. Ekimov EA, Sidorov VA, Bauer ED, Mel'nik NN, Curro NJ, et al. (2004) Superconductivity in diamond. Nature 428: 542-545.

10. Czerw R, Terrones M, Charlier JC, Blasé X, Foley B, et al. (2001) Identification of electron donor states in N-doped carbon nanotubes. Nano Lett 1: 457-460.

11. Xia Y, Mokaya R (2004) Synthesis of ordered mesoporous carbon and nitrogendoped carbon materials with graphitic pore walls via a simple chemical vapor deposition method. Adv Mater 16: 1553-1558.

12. Wei D, Liu Y, Wang Y, Zhang H, Huang L, et al. (2009) Synthesis of N-doped graphene by chemical vapor deposition and its electrical properties. Nano Lett 9: $1752-1758$.

13. Wang CD, Zhou YA, He LF, Ng TW, Hong G, et al. (2013) In situ nitrogendoped graphene grown from polydimethylsiloxane by plasma enhanced chemical vapor deposition. Nanoscale 5: 600-605.

14. Li X, Wang H, Robinson JT, Sanchez H, Diankov G, et al. (2009) Simultaneous nitrogen doping and reduction of graphene oxide. J Am Chem Soc 131: 15939 15944. 
Citation: Mannan MA, Hirano Y, Quitain AT, Koinuma M, Kida T (2018) Boron Doped Graphene Oxide: Synthesis and Application to Glucose Responsive Reactivity. J Material Sci Eng 7: 492. doi: 10.4172/2169-0022.1000492

Page 6 of 6

15. Kumar NA, Nolan H, McEvoy N, Rezani E, Doyle RL, et al. (2013) Plasmaassisted simultaneous reduction and nitrogen doping of graphene oxide nanosheets. J Mater Chem A 1: 4431-4435.

16. Wei Q, Tong X, Zhang G, Qiao J, Gong Q, et al. (2015) Nitrogen-doped carbon nanotube and graphene materials for oxygen reduction reactions. Catalysts 5 : 1574-1602.

17. Li S, Wang Z, Jiang H, Zhang L, Ren J, et al. (2016) Plasma-induced highly efficient synthesis of boron doped reduced graphene oxide for supercapacitors. Chem Commun 52: 10988-10991.

18. Yeom DY, Jeon W, Tu NDK, Yeo SY, Lee SS, et al. (2015) High-concentration boron doping of graphene nanoplatelets by simple thermal annealing and their supercapacitive properties. Sci Rep 5: 09817.

19. Umrao S, Gupta TK, Kumar S, Singh VK, Sultania MK, et al. (2015) Microwaveassisted synthesis of boron and nitrogen co-doped reduced graphene oxide for the protection of electromagnetic radiation in Ku-Band. ACS Appl Mater Interfaces 7: 19831-19842.

20. Allahbakhsh A, Sharif F, Mazinani S, Kalaee MR (2014) Synthesis and characterization of graphene oxide in suspension and powder forms by chemical exfoliation method. Int J Nano Dimens 5: 11-20.

21. Miller GL (1959) Use of dinitrosalicylic acid reagent for determination of reducing Sugar. Anal Chem 31: 426-428.

22. Song J, Wang X, Chang CT (2014) Preparation and characterization of graphene oxide. J Nanomater 2014.

23. Zhang C, Hao R, Liao H, Hou Y (2013) Synthesis of aminofunctionalized graphene as metal-free catalyst and exploration of the roles of various nitrogen states in oxygen reduction reaction. Nano Energy 2: 88-97.

24. Ram S, Ram K (1989) IR and Raman studies and effect of y radiation on crystallization of some lead borate glasses containing $\mathrm{Al}_{2} \mathrm{O}_{3}$. J Mater Sci 23:4541-4546

25. Jacox ME, Irikura KK, Thompson WE (2000) The reaction of $\mathrm{BF}_{3}$ with $\mathrm{H}_{2} \mathrm{O}$ :Infrared spectrum of $\mathrm{BF}_{2} \mathrm{OH}$ trapped in solid neon. J Chem Phy 113: 57055710 .
26. Gago R, Jimenez I, Agullo-Rueda F, Albella JM, Czigany LZ, et al. (2002) Transition from amorphous boron carbide to hexagonal boron carbon nitride thin films induced by nitrogen ion assistance. Appl Phys 92: 5177-5182.

27. Eda G, Fanchini G, Chhowalla M (2008) Large-area ultrathin films of reduced graphene oxide as a transparent and flexible electronic material. Nat Nanotechnol 3: 270-274

28. Chen W, Yan L, Bangal PR (2010) Preparation of graphene by the rapid and mild thermal reduction of graphene oxide induced by microwaves. Carbon 48 $1146-1152$.

29. Panchakarla LS, Subrahmanyam KS, Saha SK, Govindaraj A, Krishnamurthy HR, et al. (2009) Synthesis, structure, and properties of boron- and nitrogendoped graphene. Adv Mater 21: 4726-4730.

30. Sahoo M, Sreena KP, Vinayan BP, Ramaprabhu S (2015) Green synthesis of boron doped graphene and its application as high performance anode material in Li ion battery. MRS Bulletin 61: 383-390.

31. Duan X, Ao Z, Sun H, Indrawirawan S, Wang Y, et al. (2015) Nitrogen-doped graphene for generation and evolution of reactive radicals by metal-free catalysis. ACS Appl Mater Interfaces 7: 4169-4178.

32. Li X, Cheng $\mathrm{Y}$, Zhang $\mathrm{H}$, Wang S, Jiang Z, et al. (2015) Efficient $\mathrm{CO}_{2}$ capture by functionalized graphene oxide nanosheets as fillers to fabricate multipermselective mixed matrix membranes. ACS Appl Mater Interfaces 7: 5528-5537.

33. Fang $\mathrm{H}$, Yu C, Ma T, Qiu J (2014) Boron-doped graphene as a high-efficiency counter electrode for dye-sensitized solar cells. Chem Commun 50: 3328-3330.

34. Hishiyama Y, Irumano H, Kaburagi Y, Soneda Y (2001) Structure, Raman scattering, and transport properties of boron-doped graphite. Phys Rev B 63 : 245406.

35. Ferrier RJ, Prasad R (1965) Boric acid derivatives as reagents in carbohydrate chemistry. 6. phenylboronic acid as a protecting group in disaccharide synthesis. J Chem Soc, pp: 7429-7432.

36. Eggert H, Frederiksen J, Morin C, Norrild JC (1999) A new glucose-selective fluorescent bisboronic acid. First report of strong alpha-furanose complexation in aqueous solution at physiological pH. J Org Chem 64: 3846-3852. 